\title{
Hemisection: Two case reports
}

\section{Seda Falakaloglu ${ }^{1}$, Ozkan Adiguzel $^{1}$, Faruk Oztekin ${ }^{2}$, Yalcin Deger ${ }^{3}$, Gokhan Ozdemir ${ }^{3}$}

${ }^{1}$ Dicle University, Faculty of Dentistry, Department of Endodontics, Diyarbakır, Turkey.

${ }^{2}$ Firat University, Faculty of Dentsitry, Department of Endodontics, Diyarbakır, Turkey.

${ }^{3}$ Dicle University, Faculty of Dentsitry, Department of Prosthodontics, Diyarbakır, Turkey.

Correspondence:

Seda Falakaloglu

Dicle University, Faculty of

Dentistry, Department of

Endodontics,

Diyarbakir, Turkey

e-mail: sedafalakaloglu@gmail.com

Received 19 October 2015

Accepted 16 February 2016

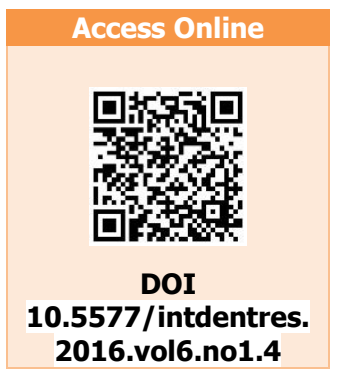

\section{Introduction}

Modern developments in dentistry have led to the development of safer treatment techniques. Clinicians may opt for special treatment of endodontic and periodontal problems in patients presenting with a furcation not affecting the root in well-established teeth (1). Hemisection represents one method for the restoration of chewing function and the preservation of teeth through prosthetic restoration (2). Hemisection involves dividing from the mesial surface to the distal surface on the upper molars and premolars, and from the buccal surface to the lingual surface on the lower molars. The basic principle of this operation is that parts of affected teeth can be removed if they fail to function properly so that a healthy periodontal environment is created (3). The success of hemisection depends on multidisciplinary study and correct diagnosis (4). Application of endodontic, surgical, and 
prosthodontic treatment in the processed areas must be cautiously and accurately applied and must progress in steps (5). Hemisection indicators include advanced periodontitis in the infected area and a perforated superficial cervical region. Contraindications are deep furcation perforation, conjoined roots that cannot be restored, and teeth that have short or unsuccessful canal treatments (6). This article describes two problematic lower first molars, and presents the endodontic periodontal and prosthodontics aspects of treatment, as well as prognosis and follow-up for this treatment.

\section{Case Report}

\section{FIRST CASE}

A 21-year-old woman presented with pain and swelling in the lower left first molar and was admitted to the clinic at Dicle University, Faculty of Dentistry, Department of Endodontics. As a result of the examination it was decided that evaluation of a prior root canal treatment by radiography should be performed because the apical region of the distal root canal could not be identified due to root calcification (Figure 1-a).

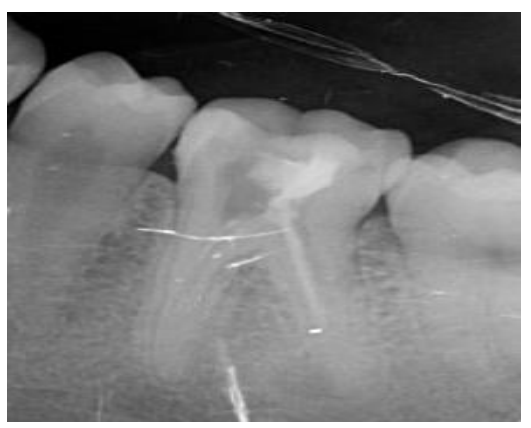

Figure 1-a. Intraoral view before surgery operation.

It was decided that a hemisection would be performed on the healthy mesial root with furcation. Canal length type $\mathrm{K}$ files (\#15) were selected based on the canal cavity opening and shaped using a RECIPROC R25 (VDW GmbH). Irrigation with 2.5\% $\mathrm{NaOCl}$ and $17 \%$ EDTA was performed, and sterile paper points were used to dry the tooth. Simple root canal treatment was performed using guttapercha/Sealapex (Kerr). Large canal input cavities were closed with zinc phosphate cement. The patient was given an appointment for a week after the procedure. On that date, dental fissure burs were used to remove part of the tooth by furcation at the distal root, as shown in Figure 1-b.

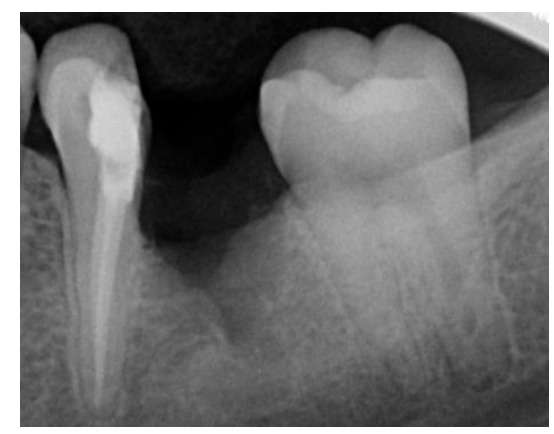

Figure 1-b. Appearance of radiolucent lesion.

The following month, the mesial region at the root was examined for any problems resulting from the root canal treatment, and the patient was referred to the Department of Prosthodontics. The mesial root space and second molar were checked, and a distal extension ridge was planned. After preparation, a two-step putty-wash impression was taken (Elite P\&P Zhermack, Germany) and scanned, and a model was fabricated by CAM (LAVA Form). The restoration was checked for centric, lateral, and protrusive contacts. After CoJet sanding (silica coating with 30 silica-modified alumina particles) and silanization, the restoration was cemented with resin (Variolink Ivoclar, Vivadent, Schaan, Liechtenstein) (Figure 1-c).

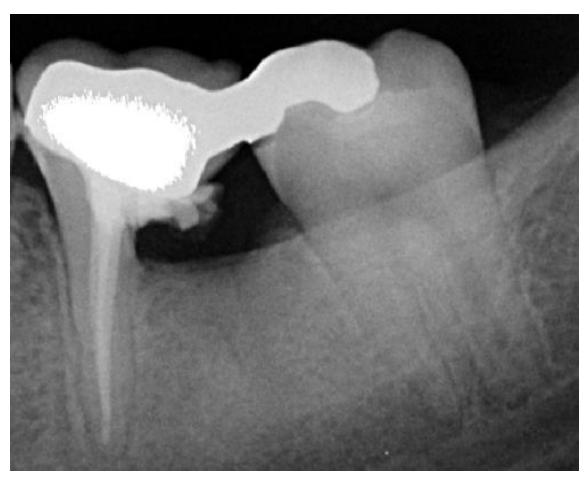

Figure 1-c. After surgery operation.

\section{SECOND CASE}

A 27-year-old woman suffering from pain and swelling around the lower-right first molar was admitted to the clinic at Dicle University, Faculty of Dentistry, Endodontics Department. Radiography 
revealed external root resorption and apical periodontitis in the mesial root of the tooth (Figure 2-a). It was decided to separate the lingual from the buccal root by furcation rather than performing root amputation due to the surrounding healthy teeth. Canal length type K files (\#15) were selected for the canal input cavity opening and shaped by RECIPROC R25(VDW GmbH). Irrigation with $2.5 \% \mathrm{NaOCl}$ and $17 \%$ EDTA was applied. Sterile paper points were used to dry the tooth. The root canal treatment was completed using gutta-percha/Sealapex (Kerr) as the simplest technique (Figure 2-b). Large canal input cavities were closed with zinc phosphate cement. The patient was given an appointment for a week after the procedure.

On that date, dental fissure burs were used to divide the tooth mesiodistally and the mesial root was extracted. A month later, the patient was referred to the Department of Prosthodontics for examination of the distal root and to identify any problems in the treatment of the root canal. The present case was treated using an alternative prosthesis (the inlay was supported with a metal ceramic bridge using metal-ceramic inlays as retainers on the mandibular second premolar and first molar). The provisional restorations were maintained intraorally for 8 weeks before the final impressions were made, thus allowing sufficient time for evaluation. Inlay cavity preparations were done on teeth \#46 and \#45 in preparation for receiving the resin-bonded retainers.

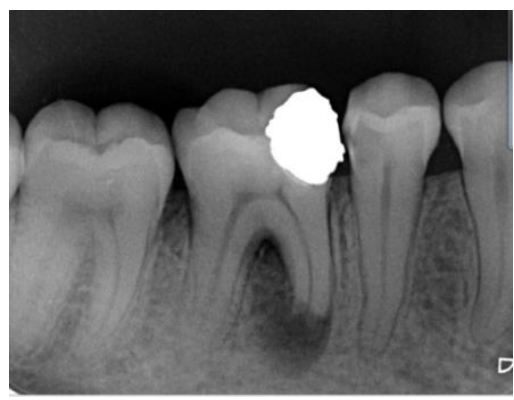

Figure 2-a. Intraoral view after surgery operation.

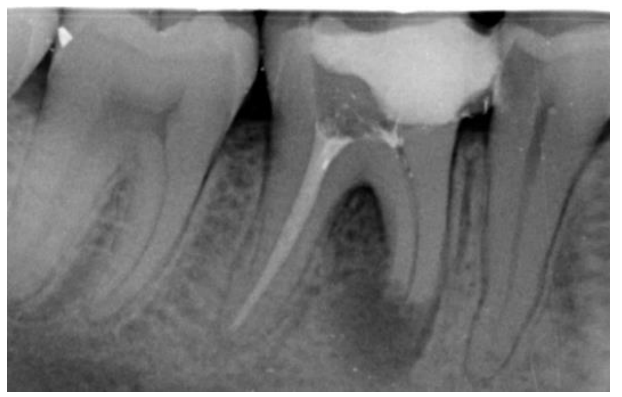

Figure 2-b. Histopathological view
The teeth were then cemented provisionally to evaluate the occlusion. Complete arch impressions were made using polymerization silicone impression material (Elite P\&P Zhermack, Germany). The cavity was rinsed and dried, avoiding dehydration, and then primer and bonding adhesive were applied according to the manufacturer's instructions (CLEARFIL SE Bond, Kuraray Medical, Tokyo, Japan) and light-cured for 15 seconds. CoJet sanding (silica coating with $30 \mu \mathrm{m}$ silica-modified alumina particles) and silanization were performed. The restoration was cemented with resin (PANAVIA 21, Kuraray, Japan). Post-operative care instructions were given to the patient, and periodic recall visits were advised. Daily flossing and use of a Proxabrush or Sulcabrush were recommended (Figure 2-c).

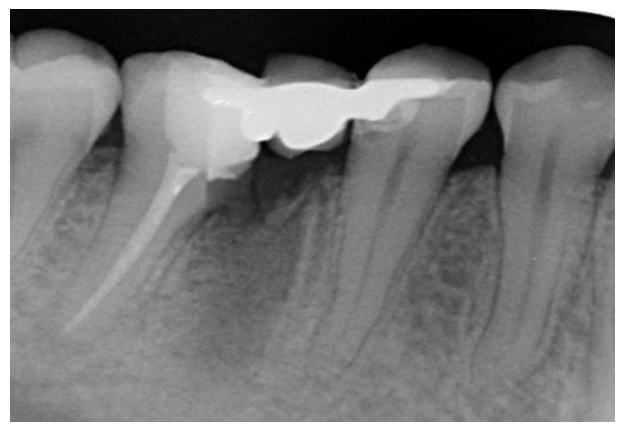

Figure 2-c. Histopathological view

\section{Discussion}

Hemisectioning of well-rooted teeth has been shown to be a useful treatment to prevent shooting pain (7), and restoration of healthy teeth, especially furcated molars of the lower jaw, is known to influence chewing function (8). The success of this treatment depends on correct case evaluation. A resection method can be applied when there is adequate bone support around the root, but adequate root size is also important for appropriate prognosis and treatment (9). However, a disadvantage of this procedure is the requirement for remaining roots, and root canal treatments and prosthetics must be refreshed. For treatment to be successful, it is very important that the endodontic treatment can also be maintained in the remaining parts of the prostheses. The amount of bone support around the remaining root is another important factor for successful fixed prostheses. Another factor to consider in restoration success is whether the portion of root remaining is greater than the amount of bone supporting the fixed prostheses (10). These cases can be restored using different prosthetic treatment approaches. Resinlinked and adhesive-fixed partial denture 
restorations and resin bonded fixed prostheses are an alternative to full crowns.

Using an inlay as a retainer in the present case represented a more conservative preparation for restoring periodontal health while causing less pulpal damage. Compared with inlay preparations, full crowns cause more damage to vital tissues and create improper gingival margins, which might worsen periodontal health. Hemisection allows for physiological mobility of the remaining root, which is a more suitable abutment for fixed partial dentures than its osseointegrated counterpart (11). Prosthetic restoration, done properly and managed well, is important for the success of periodontal treatments $(12,13)$. Hemisection in cases of mandible tooth root canal makes later surgical processes easier because it is difficult to perform endodontic treatment during bleeding, as anatomical markers cannot be seen clearly (14).

Anatomical markers are very important for the lower first molar tooth during the hemisection phase. The bifurcation of the region representing the enameloma is important and may not be possible in every case. Some teeth also may require a crown lengthening procedure or extrusion if there is severe decay on the tooth crown $(15,16)$. Although treatment of the mesial root canal is more difficult than the distal root, this may determine which root will be amputated, depending on the success of endodontic treatment (3).

In the first case described above, the distal root was amputated because of calcification of the root canal, and in the second, the mesial root was amputated due to endodontic-periodontal lesions and external root resorption. In the first case described above, the tooth was amputated at the distal root tip, and the second mesial root has to be amputated due to endodontic-periodontal lesions and external root resorption. From the perspective of conservative dentistry, hemisection is important to prevent extraction of the tooth. We believe that hemisection, as a multidisciplinary treatment approach comprising endodontic, restorative surgery, and prosthodontics represents an alternative treatment option for teeth and bone structure preservation $(17,18)$.

\section{Conclusions}

Hemisection, or removal of the diseased part of a well-established tooth having a lesion extending into the root, together with prosthetic treatment of the remaining tooth, is considered a conservative procedure that improves shooting pain and oral health, and allows continuation of normal chewing function. Hemisection is a conservative treatment method that prevents tooth extraction because the diseased part of a well-established tooth with a lesion extending into the root is removed. This also improves any pain and oral health, and allows the continuation of normal chewing function with prosthetic treatment. The success of the treatment is directly related to the choice of cases. Successful results are obtained when the correct indications are present, according to the rules of hemisection therapy, during the monitoring phase. Hemisection may be a suitable alternative to tooth extraction for effective and conservative treatment of diseased teeth.

\section{Acknowledgments}

The authors deny any conflicts of interest related to this study.

\section{References}

1. Nasr AMSD, Nasr $H$. Root resection revisited. Periodontal Abstracts 2001; 49(3): 69-74.

2. Parmar G, Vashi P. Hemisection: a case-report and review. Endodontology. 2003;15:26-9.

3. Alaçam T. (2012); Endodonti, Özyurt Matbaacılık, Ankara.

4. Haueisen $H$, Heidemann D. Hemisection for treatment of an advanced endodonticperiodontal lesion. Int Endod J 2002;35:557-72. Crossref

5. Kurtzman GM, Mahesh L, Qureshi I. Hemisection as an alternative treatment for the vertically fractured mandibular molar. J Pak Dent Assoc. 2012;21(3): 177-81.

6. Çalışkan MK. Endodontide Tanı ve Tedaviler, Nobel Tıp Kitapevleri İstanbul, 2006.

7. Yadav S, Agnihotri K, Vinayak V, Gurtu A. Hemisection-Divide \& rule: A case report. Journal of Dental Sciences \& Oral Rehabilitation 2012;3(4):54-6.

8. Akki S, Mahoorkar S. Tooth hemisection and restoration-an alternative to extraction-A case report. International Journal of Dental Clinics 2011:3(3):67-8

9. Şahinkesen G, Tunca YM, Ertan T. Yetersiz kanal tedavisi yapılmış ve furka defektli alt ikinci daimi molar dişin kombine tedavisi: Olgu Sunumu Turkiye Klinikleri J Dental Sci 2005 11:73-6

10. Saad MN, Moreno J, Crawford C. Hemisection as an alternative treatment for decayed multirooted terminal abutment: a case report. J Can Dent Assoc. 2009;75(5):387-90.

11. Kharbanda A, Bali R, Sharma V, Sood P. Hemisection: an alternative prosthetic 
management. Indian Journal of Dental Sciences 2012;5(4):74-6.

12. Shah S, Modi B, Desai K, Duseja S. HemisectionA conservative approach for a periodontally compromised tooth-A Case Report Journal of Advanced Oral Research, Vol 3; Issue 2: May-Aug 2012

13. Agüloğlu S, Ayna E, Özdemir E. A FibreReinforced fixed partial denture on a hemisectioned tooth: A Case Report. Int Dent Res 2011;1:38-41. Crossref

14. Lawande SA, Lawande GS. Hemisection as a viable treatment option for furcation-involved mandibular molar. J Pharm Biomed Sci 2013;35:1830-3.

15. Kılıç D, Arzu Alkan B, Kılıç K. Use of a surgical guide in a crown lengthening procedure to improve the aesthetics of the interdental papillae: A case report. Int Dent Res 2012;2(3):75-80. Crossref

16. Yiğit Özer S, Uysal İ, Bahşi E. Surgical extrusion of a complete crown fractured tooth: A case report. Int Dent Res 2011;2:70-4. Crossref

17. Agüloğlu S, Ayna E, Özdemir E. A FibreReinforced Fixed Partial Denture on a Hemisectioned Tooth: A Case Report. Int Dent Res 2011;1:38-41. Crossref

18. Nowokowski AT, Serebnitski A, Pesun IJ. Hemisection as a treatment option: A case report. Oral Health, 2010 - oralhealthjournal.com 